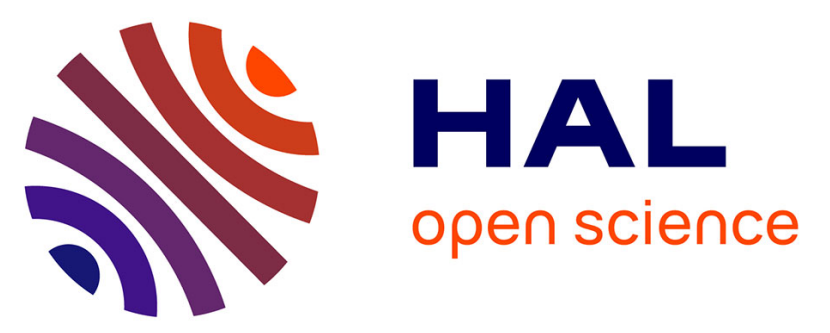

\title{
Prognostic Factors and Oncologic Outcome in 146 Patients with Colorectal Peritoneal Carcinomatosis Treated with Cytoreductive Surgery Combined with Hyperthermic Intraperitoneal Chemotherapy: Italian Multicenter Study S.I.T.I.L.O
}

F. Cavaliere, M. de Simone, S. Virzì, M. Deraco, C.R. Rossi, A. Garofalo, F. Di Filippo, D. Giannarelli, M. Vaira, M. Valle, et al.

\section{- To cite this version:}

F. Cavaliere, M. de Simone, S. Virzì, M. Deraco, C.R. Rossi, et al.. Prognostic Factors and Oncologic Outcome in 146 Patients with Colorectal Peritoneal Carcinomatosis Treated with Cytoreductive Surgery Combined with Hyperthermic Intraperitoneal Chemotherapy: Italian Multicenter Study S.I.T.I.L.O. EJSO - European Journal of Surgical Oncology, 2011, 37 (2), pp.148. 10.1016/j.ejso.2010.10.014 . hal-00663067

\section{HAL Id: hal-00663067 https://hal.science/hal-00663067}

Submitted on 26 Jan 2012

HAL is a multi-disciplinary open access archive for the deposit and dissemination of scientific research documents, whether they are published or not. The documents may come from teaching and research institutions in France or abroad, or from public or private research centers.
L'archive ouverte pluridisciplinaire HAL, est destinée au dépôt et à la diffusion de documents scientifiques de niveau recherche, publiés ou non, émanant des établissements d'enseignement et de recherche français ou étrangers, des laboratoires publics ou privés. 


\section{Accepted Manuscript}

Title: Prognostic Factors and Oncologic Outcome in 146 Patients with Colorectal Peritoneal Carcinomatosis Treated with Cytoreductive Surgery Combined with Hyperthermic Intraperitoneal Chemotherapy: Italian Multicenter Study S.I.T.I.L.O

Authors: F. Cavaliere, MD M. De Simone, MD S. Virzì, MD M. Deraco, MD C.R.

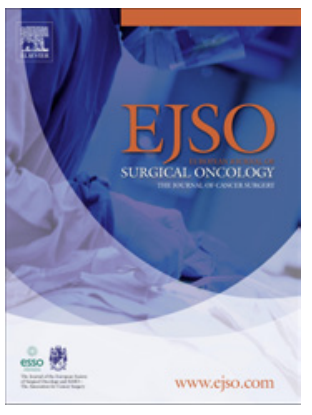
Rossi, MD A. Garofalo, MD F. Di Filippo, MD D. Giannarelli, MS M. Vaira, MD M. Valle, MD P. Pilati, MD P. Perri, MD M. La Pinta, MD I. Monsellato, MD F. Guadagni, MD

PII: S0748-7983(10)00556-1

DOI: 10.1016/j.ejso.2010.10.014

Reference: $\quad$ YEJSO 3071

To appear in: European Journal of Surgical Oncology

Received Date: 24 March 2010

Accepted Date: 26 October 2010

Please cite this article as: Cavaliere F, De Simone M, Virzì S, Deraco M, Rossi CR, Garofalo A, Di Filippo F, Giannarelli D, Vaira M, Valle M, Pilati P, Perri P, La Pinta M, Monsellato I, Guadagni F. Prognostic Factors and Oncologic Outcome in 146 Patients with Colorectal Peritoneal Carcinomatosis Treated with Cytoreductive Surgery Combined with Hyperthermic Intraperitoneal Chemotherapy: Italian Multicenter Study S.I.T.I.L.O, European Journal of Surgical Oncology (2010), doi: 10.1016/ j.ejso.2010.10.014

This is a PDF file of an unedited manuscript that has been accepted for publication. As a service to our customers we are providing this early version of the manuscript. The manuscript will undergo copyediting, typesetting, and review of the resulting proof before it is published in its final form. Please note that during the production process errors may be discovered which could affect the content, and all legal disclaimers that apply to the journal pertain. 
Prognostic Factors and Oncologic Outcome in 146 Patients with Colorectal Peritoneal Carcinomatosis Treated with Cytoreductive Surgery Combined with Hyperthermic Intraperitoneal Chemotherapy: Italian Multicenter Study S.I.T.I.L.O.

F. Cavaliere, MD ${ }^{\mathrm{a}}$, M. De Simone, $\mathrm{MD}^{\mathrm{b}}, \mathrm{S}$. Virzì, $\mathrm{MD}^{\mathrm{c}}$, M. Deraco, MD ${ }^{\mathrm{d}}$, C.R. Rossi, MD ${ }^{\mathrm{e}}$, A. Garofalo, MD ${ }^{\mathrm{f}}$, F. Di Filippo, $\mathrm{MD}^{\mathrm{f}}$, D. Giannarelli, $\mathrm{MS}^{\mathrm{g}}, \mathrm{M}$. Vaira, MD ${ }^{\mathrm{b}}, \mathrm{M}$. Valle, $\mathrm{MD}^{\mathrm{f}}$, P. Pilati, MD ${ }^{\mathrm{e}}$, P. Perri, MD ${ }^{\mathrm{f}}$, M. La Pinta, MD ${ }^{\mathrm{a}}$, I. Monsellato MD ${ }^{\mathrm{a}}$, F. Guadagni, MD ${ }^{\mathrm{h}}$.

${ }^{\text {aa } D e p a r t m e n t ~ o f ~ S u r g e r y, ~ S a n ~ G i o v a n n i ~ H o s p i t a l, ~ V i a ~ d e l l ' A m b a ~ A r a d a m ~ 9, ~} 00184$ Rome, Italy; francescocavaliere@fastwebnet.it

${ }^{\mathrm{b}}$ Department of Surgery, Surgical Oncology Unit, San Giuseppe Hospital, Viale Giovanni Boccaccio, 50053 Empoli FI, Italy; m.desimone@us111.tos.it

${ }^{\mathrm{c}}$ General Surgery Unit, Bentivoglio Hospital, Via Marconi, 35 - 40010 Bentivoglio, Bologna, Italy; salvatore.virzi@ausl.bo.it

${ }^{\mathrm{d}}$ Department of Surgery, Melanoma Sarcoma Unit, National Cancer Institute, Via Giacomo Venezian 1, 20133 Milan, Italy;

${ }^{\mathrm{e}}$ Department of Oncological and Surgical Sciences, University of Padova, Via Gattamelata 64, 35128 Padova, Italy;

${ }^{\mathrm{f}}$ Surgical Oncology, Regina Elena National Cancer Institute, Via Elio Chianesi 53, 00144 Rome, Italy; garofalo@ifo.it

${ }^{\mathrm{g}}$ Biostatistical Unit, Regina Elena National Cancer Institute Via Elio Chianesi 53, 00144 Rome, Italy; guadagni@ifo.it

${ }^{\mathrm{h}}$ Department of Laboratory Medicine and Advanced Biotechnology, IRCCS san Raffaele Pisana, Via della Pisana 235, 00163, Rome, Italy; fiorella.guadagni@sanraffaele.it

Correspondence to:

Francesco Cavaliere

Via Tor Fiorenza, 13, 00199 Rome - Italy

Tel. 0039338 2937544; $\quad$ Fax. 0039677055549

e-mail: francescocavaliere@ fastwebnet.it

Running head: colorectal peritoneal carcinomatosis 


\begin{abstract}
Aim: The present study was specifically designed to assess the major clinical and pathological variables of patients with colorectal peritoneal carcinomatosis in order to investigate whether currently used criteria appropriately select candidates for peritonectomy procedures (cytoreductive surgery) combined with hyperthermic intraperitoneal chemotherapy (HIPEC).
\end{abstract}

Patients and Methods: Preoperative, operative and follow-up data on 146 consecutive patients presenting with peritoneal carcinomatosis of colorectal origin and treated by surgical cytoreduction combined with HIPEC in 5 Italian Hospital and University centers were prospectively entered in a common data-base. Univariate and multivariate analyses were used to assess the prognostic value of clinical and pathologic factors.

Results: Over a minimum 24-month follow-up, the overall morbidity rate was $27.4 \%$ (mortality rate: $2.7 \%$ ) and was directly related to the extent of surgery. Peritoneal cancer index (PCI), unfavorable peritoneal sites, synchronous or previously resected liver metastasis and the completeness of cytoreduction, all emerged as independent prognostic factors correlated with survival.

Conclusions: Until research provides more effective criteria for selecting patients based upon the biomolecular features of carcinomatosis, patients should be selected according to the existing independent prognostic variables.

Key Words: Prognostic factors-Colorectal carcinoma-Peritoneal carcinomatosisCytoreductive surgery-Intraperitoneal chemotherapy. 


\section{INTRODUCTION}

Strategies for managing peritoneal carcinomatosis have fundamentally changed over the past 15 years. Research into tumor spreading has shown, indeed, that development of malignant cell implants on the peritoneal layer is a more efficient process than hematogenous spread, possibly because the peritoneum is a more favorable host than other organs for tumor proliferation [1]. Hence peritoneal spread can develop without distant metastasis. These observations are consistent with the clinical finding that in as many as 30\% of patients with colorectal adenocarcinoma disease progression eventually leads to synchronous (8-10\%) or metachronous colorectal peritoneal carcinomatosis $(25 \%)[2,3]$. The concept has, therefore, emerged that since some peritoneal carcinomatosis, including those of colorectal origin, are a form of locoregional cancer dissemination, they should be treated with a locoregional approach [4].

An aggressive locoregional approach, including peritonectomy procedures (cytoreductive surgery-CRS) combined with hyperthermic intraperitoneal chemotherapy (HIPEC) has effectively altered the history of colorectal peritoneal carcinomatosis. Median survival rates are approaching 2 years along with long-term survival ranging from about $22 \%$ to $49 \%$ [5-7]. This combined treatment approach is nevertheless costly, time-consuming, and carries high morbidity and mortality rates that come within acceptable ranges only after a lengthy learning curve [8-9].

Ample evidence $[7,10]$ now shows that the therapeutic index for integrated treatment closely depends on patient selection, a criterion which is currently assessed by clinical and quantitative prognostic indicators, based on the extent of peritoneal disease and likelihood of achieving complete or optimal cytoreduction. Hence selecting patients with less extensive carcinomatosis and with a higher likelihood of achieving complete cytoreduction would presumably increase survival rates for treated patients and at the same time reduce the rates of 
surgical complications. On the other hand, using excessively strict patient selection criteria might lead to underestimate patients that might be cured, leaving them untreated and without other alternative therapeutic options. Inappropriate patient selection therefore remains a major concern.

In this study we prospectively collected clinical data for a consecutive series of 146 patients with colorectal peritoneal carcinomatosis who underwent cytoreductive surgery combined with HIPEC in order to investigate whether currently used criteria appropriately select candidates for such treatment procedure. 


\section{PATIENTS AND METHODS}

\section{Patients}

Preoperative, operative and follow-up data on 146 consecutive patients, presenting with peritoneal carcinomatosis of colorectal origin and treated by surgical cytoreduction combined with HIPEC in 5 Italian Hospital and University centers, were entered into a database over a period from April 1995 to April 2007. The study began in two centers and then, in more recent years, three other joined them. Patients' characteristics are summarized in Table 1. Clinical and surgical records, diagnostic imaging, laboratory and pathology reports were prospectively entered into the database and regularly updated according to a study protocol designed in the 1990s for the Italian Society of Locoregional Cancer Therapies in Oncology (SITILO) and subsequently updated as knowledge progressed.

Preoperative work-up always included a total-body contrast enhanced computed tomography (CT) to stage peritoneal disease and exclude distant metastases, upper gastrointestinal endoscopy and colonoscopy. Further positron emission tomography (PET) evaluation was left at surgeon's discretion. Each patient also underwent a detailed preoperative evaluation to assess physical conditions and calculate performance status. Prognostic indicators included both the Sugarbaker peritoneal cancer index (PCI) and the completeness of cytoreduction (CCR) score. The PCI was evaluated intraoperatively to quantify the extent of disease as a numerical score (0-39). The CCR score is an index that quantifies the extent of residual disease in four categories: CCR0 is no residual macroscopic disease; CCR1 is residual tumor less than $2.5 \mathrm{~mm}$; CCR2 is residual tumor between $2.5 \mathrm{~mm}$ and $2.5 \mathrm{~cm}$, and CCR3 is residual tumor more than $2.5 \mathrm{~cm}$ or confluent nodules [11].

Contraindications to surgical cytoreduction combined with HIPEC included the presence of extra-abdominal or unresectable intra-abdominal disease, including unresectable hepatic metastasis, poor general conditions or performance status $>2$ according to the Eastern 
Cooperative Oncology Group (ECOG) and an age of $>76$ years. All patients gave their informed consent and the study protocol was approved by the Medical Ethical Committee of each center.

\section{Surgical procedure and HIPEC}

Cytoreductive surgery consisted of the major peritonectomy procedures proposed by Sugarbaker [12] and reappraised by SITILO [11-14].

Patients with CCR0-1 were further subjected to HIPEC. The choice of perfusion modality (open, semi-closed or closed techniques) was left to the operator's discretion. To continuously monitor peritoneal temperature, thermocouples were placed in most regions of the abdominal cavity. During perfusion, a heat exchanger kept the perfusate at approximately $45^{\circ} \mathrm{C}$ thus maintaining the intracavitary perfusate at $41.5^{\circ} \mathrm{C}-43^{\circ} \mathrm{C}$, i.e., a temperature range previously shown to act synergically with the antiblastic drugs used, while maintaining regional toxicity at acceptable levels [15]. Over the 12-year study the drugs perfused were cisplatinum (25 $\mathrm{mg} / \mathrm{m}^{2} / 1$ of perfusate), or cisplatinum $\left(25 \mathrm{mg} / \mathrm{m}^{2} / \mathrm{l}\right)$ plus mitomycin-C $\left(3.3 \mathrm{mg} / \mathrm{m}^{2} / \mathrm{l}\right)$, and perfusion lasted 60-90 minutes. A group of 11 patients treated more recently (2005-2007) according to the Elias protocol [16] received HIPEC with oxaliplatin perfused at a dose of $460 \mathrm{mg} / \mathrm{m}^{2}$ in $21 / \mathrm{m}^{2}$ of $5 \%$ dextrose at a temperature of $42-44^{\circ} \mathrm{C}$ over $30 \mathrm{~min}$ and intravenous administration of 5-FU $\left(400 \mathrm{mg} / \mathrm{m}^{2}\right)$ and leucovorin $\left(20 \mathrm{mg} / \mathrm{m}^{2}\right)$.

The choice of constructing an ileostomy was left to the individual surgeon's discretion. All patients were admitted to the postoperative intensive care unit (ICU) for at least 24 hours. Clinical data were recorded on a standard database form and evaluated by a single investigator. Systemic toxicity was defined according to the World Health Organization (WHO) criteria. Locoregional HIPEC-related toxicity was scored according to a modified Ozols classification. [17]. Median follow-up was calculated from the date of surgery to last follow-up assessment or death. 


\section{Statistical analysis}

Differences in rates were tested by chi-square or Fisher's exact test according to sample size. Survival was analyzed with Kaplan-Meier's method and the log-rank test was used to compare survival curves. Standard probability cut-off, $P \leq .05$, was chosen as significance level. Cox proportional-hazards model was used to investigate the role of prognostic factors in outcome and $P$-values $<.10$ were considered significant. Data were analyzed using the Statistical Package for Social Sciences (SPSS Inc., Chicago, IL), version 11.0. 


\section{RESULTS}

\section{Combined treatment and complications}

Upon admittance $11 \%$ of the patients had symptoms of bowel occlusion and $6.2 \%$ had a history of previously resected liver metastases or liver metastases synchronous with peritoneal carcinomatosis. Seventy-six percent of the patients had undergone previous surgery, mostly for primary adenocarcinoma and $68 \%$ had already received systemic chemotherapy either as adjuvant or as palliative treatment with 5-fluorouracil and leucovorin or, less frequently, with cisplatin, mitomycin-C, oxaliplatin and irinotecan singly or combined with other antineoplastic drugs. In $49 \%$ of the patients the PCI ranged from 10 to 20 , whereas in $18 \%$ PCI exceeded 20.

Total peritonectomy was required in $25 \%$ of the patients. Complete cytoreduction (CCR score 0) was achieved in $851 \%$ and optimal cytoreduction (CCR score 1) in $7.5 \%$ of the cases. In $31 \%$ of the patients cytoreductive surgery required more than 2 intestinal anastomoses. All patients with CCR scores of 0 or 1 underwent HIPEC: $58.9 \%$ were open and $41.1 \%$ closed procedures. The combined surgical procedure lasted a mean 510 minutes. The mean hospital stay was 25 days (median 20; range 8-94 days).

Major morbidity occurred in $27.4 \%$ of the cases, mostly related to anastomotic leakage, fistulas or intestinal perforations $(7.4 \%)$, sepsis $(4.1 \%)$, bleeding $(2.0 \%)$, and pancreatitis or pancreatic fistulas (1.4\%). A precautionary ileostomy was constructed in $32.2 \%$ of the patients to protect the intestinal anastomoses. Overall, surgical complications were directly related to the length of surgery ( $P=.004$ at a cut-off of 10 hours $)$ and the extent of peritonectomy. The extent of disease correlated with the complication rate (11\% in patients with PCI $<11,26 \%$ in those with PCI $11-20$ and $44 \%$ in those with PCI $>20)(P=.02)$. The postoperative mortality rate was $2.7 \%$. 


\section{Follow-up data and survival analysis}

When we assessed oncologic outcome in the 146 patients, at a median follow-up of 19 months (ranging from 1 to 108 months), the 2-year overall survival rate was $45 \%$ with a median survival of 21 months, whereas the 2-year disease-free survival rate was $33 \%$, decreasing to $26 \%$ in the $3^{\text {rd }}$ year (Fig. 1).

No difference was found in survival rates for patients with synchronous or metachronous carcinomatosis or survival in relation to site of the primary tumor. Furthermore, disease-free interval elapsing between resection for the primary adenocarcinoma and the onset of peritoneal carcinomatosis was not related to survival. No significant difference in survival was observed for a disease-free interval (DFI) below or above the 24-month cut-off (median survival 21 vs 25 months). Median survival differed, though not significantly, according to the HIPEC technique used: it was longer for closed perfusion than for open perfusion (22 months vs. 17 months; $P=.08$ ). Median survival was longer in patients treated with oxaliplatin compared to the overall series (28 vs. 21 months) (Fig. 2), but the small sample size prevented us from analyzing the statistical significance of the difference. Analysis of the association between the Sugarbaker PCI for staging peritoneal malignancies and survival showed that median survival diminished as the PCI increased (23 months in patients with a PCI lower than 11, 16 months in those with a PCI between 11 and 20, and 11 months in those with a PCI greater than $20(P=.06)$. When we excluded from the analysis the data for the seven patients with liver metastases resected during peritonectomy or previously at the onset of carcinomatosis, the differences in median survival rates became statistically significant (PCI<11: 31 months; PCI 11-20: 19 months and PCI $>20: 14$ months; $P=.01$ by chi-square test). The presence of liver metastases, resected at any time during the course of disease had a significant unfavorable prognostic influence on median survival, which 
decreased from 22 months in patients with no liver metastases to 6 months in patients with liver metastases $(P<.001)$.

Disease distribution was retrospectively assessed (at the time of analysis looking at the operative notes) in relation to survival, considering as "unfavorable sites" those deemed to make complete surgical cytoreduction unlikely, such as small bowel mesenteric implants, disease extensively involving the porta hepatis or the diaphragm as well as bulky upper retroperitoneal lymph nodes. Disease involving unfavorable sites significantly worsened the prognosis (median 23 vs. 14 months; $P=.003$ by Fisher's test).

CCR score strongly correlated with survival. Indeed, the 2-year survival in patients with no macroscopic residual disease (CCR-0) was $50 \%$ (median survival 25 months). Conversely, patients with residual disease lower than $2.5 \mathrm{~mm}$ (CCR-1) had a $10 \%$ survival rate (median survival 11 months) and patients with residual disease greater than $2.5 \mathrm{~mm}$ (CCR 2-3) after peritonectomy had no 2-year survivors (median survival 8 months) $(P=.0001)$ (Fig. 3).

Cox proportional-hazards model was finally used to investigate the independent value of all above mentioned prognostic factors. When all the variables that reached statistical significance on the log-rank test were tested by multivariate analysis they all independently affected patients' survival (Table 2). 


\section{DISCUSSION}

Our median overall survival rate of 21 months compares well with published survival rates from similar series [18-20] and increases to 25 months in patients in whom cytoreductive surgery left no residual macroscopic disease. Contrary to expectations, median survival increased less accordingly to the completeness of cytoreduction in our series than in others $[10,19,20]$, probably depending on a subgroup of approximately 40 patients with widespread carcinomatosis enrolled in the early years of the study. These patients, in fact, had an unfavorable prognosis, despite cytoreductive surgery almost invariably achieved macroscopically complete cytoreduction.

The observed mortality rate of $2.7 \%$, due to $10 \%$ of patients who developed major complications, matches the rate for advanced cancer surgery. However, the possible advantages of an ileostomy in managing complications after cytoreductive surgery combined with HIPEC remain controversial.

When we investigated variables that might help improving patient selection, thus optimizing the oncologic outcome, we found no correlation between certain clinical and pathologic indicators such as age, performance status or tumor grade with survival. Both site of primary colorectal tumor and the presence of synchronous or metachronous carcinomatosis failed to correlate with survival. Moreover, we did not show an increased incidence of surgical failure in patients with symptoms of intestinal partial occlusion, since in almost $80 \%$ of the cases cytoreductive surgery achieved CCR- 0 . The feasibility of optimal cytoreduction was among the few selection criteria applied in the early years of the study. Hence, patients with extensive small bowel involvement were only occasionally included in this treatment group.

Even though DFI is a major prognostic factor in many malignant diseases, and also in colorectal cancer, it has never been considered a prognostic factor of importance in selecting 
patients with carcinomatosis. In our series, we found an interesting (though not significant) difference between patients categorized on the basis of a 24-month DFI (21 vs. 25 months), which is in agreement with other studies showing a significant correlation between DFI and survival in patients with recurrent peritoneal carcinomatosis of colorectal origin after combined treatment [21]. In this setting, DFI seems a major prognostic factor in predicting outcome.

The Sugarbaker PCI for staging peritoneal malignancies provides no information on the tumor's metastatic potential or probable response to treatment. The lack of suitable biomolecular markers partly nullifies the currently used selection criteria and explains why the recent Consensus Conference failed to establish precise PCI values to use as a cut-off [22].

The prognostic variable that had the major influence on survival in our series, namely the completeness of cytoreduction, can be reliably assessed only at the end of surgical treatment. In any case, bulky residual tumor should always be avoided and the surgeon should probably stop, if is possible, once it is recognized that a CCR0-1 is not feasible.

The difference in biological aggressiveness might well explain our survival results in relationship to the site of disease. At first glance, they suggest that malignant foci that are hard to eradicate correlate with surgical failure. In practice, however, if the problem concerned only the possibility of achieving complete cytoreduction, the risk related to site should have no independent prognostic ability in the multivariate analysis and would carry less statistical weight than the completeness of cytoreduction. An alternative explanation is that some disease locations can themselves reflect aggressive behavior, their prognostic value remaining even after macroscopic tumor resection. This hypothesis is in agreement with Sugarbaker's distribution theory that tumor aggression levels differ according to the characteristics of the malignancy [23]. 
A finding that invites further investigation concerns the choice of the HIPEC technique to be used, given that survival was substantial different between patients treated with open, semiclosed or closed abdomen HIPEC. We speculate that since closed HIPEC leads to lower heat dispersion it induces greater toxicity and is possibly more effective than the other modalities. In a study conducted by our group at the National Cancer Institute Regina Elena in Rome in the late 1990s, we evaluated the thermal doses (heat delivered in a unit of time) delivered to three abdominal regions (subdiaphragmatic area, mesentery and pelvis) during 35 perfusions using open HIPEC. Thermal doses achieved were more homogeneous in patients whose extensive intestinal resections reduced the gutter effect. Also in this earlier study, survival rates differed in relation to thermal doses used and were slightly though not significantly better in patients who received average mesenteric thermal doses exceeding an arbitrary cut-off value of 18 months (35 vs. 28 median months) (Dr. F. Cavaliere, National Cancer Institute Regina Elena).

An especially promising antineoplastic drug that became available for HIPEC perfusion over the 12 years we reviewed is oxaliplatin. Our preliminary oxaliplatin-induced survival rate of 28 months is an extremely encouraging finding. Oxaliplatin is the most active drug as a single agent in adjuvant chemotherapy for colorectal adenocarcinoma and in metastatic disease and induces its antineoplastic effects independently from cell-cycle phases, acting synergically with hyperthermia [24]. In recently published study conducted on a series of 48 patients with colorectal carcinomatosis treated with surgical cytoreduction plus HIPEC with oxaliplatin [25] and comparing a similar number of patients, homogeneous for disease, age and performance status, treated with palliative chemiotherapy, the 5-year overall survival rate was $51 \%$ for the HIPEC group and only $13 \%$ for the palliated group.

While the currently used criteria for selecting patients with colorectal peritoneal carcinomatosis to undergo combined treatment rely mainly on disease staging, the main future 
direction is to obtain biological tumor profiles. We need to be able to predict carcinomatosis that are likely to remain within locoregional bounds and those that are likely to undergo hematogenous spread. We can then select those that will probably respond to combined treatment. The few pioneering studies available have shown specific biological and genetic patterns in target organs, for metastatic cells from a common primary tumor [26] and research in recent years has provided evidence that vascular endothelial growth factor (VEGF) influences the development of secondary distant metastases and predicts survival [27,28]. An ad interim solution could be to undertake specifically designed studies to assess each of the currently used prognostic variables through multivariate analysis and to construct a scoring system of predictive variables each carrying its own specific weight. 


\section{CONCLUSIONS}

In conclusion, careful patient selection allows a high rate of complete cytoreduction. Combined with HIPEC, complete cytoreduction results in a median survival rate of about 21 months in patients with extensive colorectal carcinomatosis. The slight treatment benefit from combined management in patients in whom surgery achieves optimal cytoreduction (CCR-1) should increase as new chemotherapy regimens for perfusion come into more widespread use. The therapeutic index should also substantially improve as research identifies more effective criteria for selecting patients increasingly based upon the biomolecular features of carcinomatosis. Meanwhile, patient selection could be improved by assigning patients a preoperative score based on the independent prognostic variables identified in the multivariate analysis.

\section{CONFLICT OF INTEREST STATEMENT}

There is no conflict of interest in connection with this paper. 


\section{REFERENCES}

1. Jayne D. Molecular biology of peritoneal carcinomatosis. Cancer Treat Res 2007;134:21-33

2. Sadeghi B, Arvieux C, Glehen O, Beaujard AC, Rivoire M, Baulieux J, Fontaumard E, Brachet A, Caillot JL, Faure JL, Porcheron J, Peix JL, François Y, Vignal J, Gilly FN. Peritoneal carcinomatosis from non-gynecologic malignancies: results of the EVOCAPE 1 multicentric prospective study. Cancer 2000;88:358-63.

3. Jayne DG, Fook S, Loi C, Seow-Choen F. Peritoneal carcinomatosis from colorectal cancer. Br J Surg 2002;89:1545-50.

4. Cavaliere F, Di Filippo F, Botti C, Cosimelli M, Giannarelli D, Aloe L, Arcuri E, Aromatario C, Consolo S, Callopoli A, Laurenzi L, Tedesco M, Di Angelo P, Giunta S, Cavaliere R. Peritonectomy and hyperthermic antiblastic perfusion in the treatment of peritoneal carcinomatosis. Eur J Surg Oncol 2000;26:486-91.

5. Cao C, Yan TD, Black D, Morris DL. A systematic review and meta-analysis of cytoreductive surgery with perioperative intraperitoneal chemotherapy for peritoneal carcinomatosis of colorectal origin. Ann Surg Oncol 2009;16:2152-65.

6. Verwaal VJ, van Ruth S, Witkamp A, Boot H, van Slooten G, Zoetmulder FA. Longterm survival of peritoneal carcinomatosis of colorectal origin. Ann Surg Oncol 2005; 12:65-71.

7. Yan TD, Black D, Savady R, Sugarbaker PH. Systematic review on the efficacy of cytoreductive surgery combined with perioperative intraperitoneal chemotherapy for peritoneal carcinomatosis from colorectal carcinoma. J Clin Oncol 2006;24:4011-9. 
8. Cavaliere F, Valle M, De Rosa B, Federici O, Giannarelli D, Garofalo A.

Peritonectomy and chemohyperthermia in the treatment of peritoneal carcinomatosis: learning curve. Tumori 2005;4:119-21.

9. Chua TC, Yan TD, Saxena A, Morris DL. Should the treatment of peritoneal carcinomatosis by cytoreductive surgery and hyperthermic intraperitoneal chemotherapy still be regarded as a highly morbid procedure?: a systematic review of morbidity and mortality. Ann Surg 2009;249:900-7.

10. Glockzin G, Schlitt HJ, Piso P. Peritoneal carcinomatosis: patients selection, perioperative complications and quality of life related to cytoreductive surgery and hyperthermic intraperitoneal chemotherapy. World J Surg Oncol 2009;7:5.

11. Sugarbaker PH. Strategies for the prevention and treatment of peritoneal carcinomatosis from gastrointestinal cancer. Cancer Invest 2005;23:155-72.

12. Sugarbaker PH. Peritonectomy procedures. Cancer Treat Res 2007;134:247-64.

13. M De Simone, M. Nano, M. Vaira. Peritonectomia centrale, laterale e della retrocavità degli epiploon. In: Nuovo Trattato di Tecnica Chirurgica. UTET, Vol 6. Torino 2006: 376-379.

14. Di Filippo F. e Cavaliere F. Peritonectomia pelvica. In: Nuovo Trattato di Tecnica Chirurgica. UTET, Vol 6. Torino 2006: 380-385.

15. Di Filippo F, Calabrò A, Giannarelli D, Carlini S, Cavaliere F, Moscarelli F, Cavaliere $\mathrm{R}$ : Prognostic variables in recurrent limb melanoma treated with hyperthermic antiblastic perfusion. Cancer 1989;63:2552-61.

16. Elias D, Bonnay M, Puizillou JM, Antoun S, Demirdjian S, El OA, Pignon JP, Drouard-Troalen L, Ouellet JF, Ducreux M. Heated intra-operative intraperitoneal oxaliplatin after complete resection of peritoneal carcinomatosis: pharmacokinetics and tissue distribution. Ann Oncol 2002;13:267-72. 
17. Ozols RF, Young RC, Speyer JL et al: Phase I and pharmacological studies of adriamycin administered intraperitoneally to patients with ovarian cancer. Cancer Res $1982 ; 42: 4265-9$.

18. Koppe MJ, Boerman OC, Oyen WJG, Bleichrodt RP. Peritoneal carcinomatosis of colorectal origin. Incidence and current treatment strategies. Ann Surg 2006;243:21222.

19. Glehen O, Kwiatkowski F, Sugarbaker PH, Elias D, Levine EA, De Simone M, Barone R, Yonemura Y, Cavaliere F, Quenet F, Gutman M, Tentes AA, Lorimier G, Bernard JL, Bereder JM, Porcheron J, Gomez-Portilla A, Shen P, Deraco M, Rat P. Cytoreductive surgery combined with perioperative intraperitoneal chemotherapy for the management of peritoneal carcinomatosis from colorectal cancer: a multiinstitutional study. J Clin Oncol 2004;22:3284-92.

20. Yan TD, Sim J and Morris DL. Selection of patients with colorectal peritoneal carcinomatosis for cytoreductive surgery and perioperative intraperitoneal chemotherapy. Ann Surg Oncol 2007;14:1807-17.

21. Verwaal VJ et Al. Recurrences after peritoneal carcinomatosis of colorectal origin treated by cytoreduction and hyperthermic intraperitoneal chemotherapy: location, treatment, and outcome. Ann Surg Oncol 2004;11:375-9.

22. Baratti D, Kusamura S, Deraco M. The fifth international workshop on peritoneal surface malignancy (Milan, Italy, December 4-6, 2006): Methodology of diseasespecific consensus. J Surg Oncol 2008;98:258-62.

23. Sugarbaker PH. Pseudomyxoma peritonei. A cancer whose biology is characterized by a redistribution phenomenon. Ann Surg 1994;219:109-11.

24. Stewart JH 4th, Shen P, Russell G, Fenstermaker J, McWilliams L, Coldrun FM, Levine KE, Jones BT, Levine EA. A phase I trial of oxaliplatin for intraperitoneal 
hyperthermic chemoperfusion for the treatment of peritoneal surface dissemination from colorectal and appendiceal cancers. Ann Surg Oncol 2008;15:2137-45.

25. Elias D, Lefevre JH, Chevalier J, Brouquet A, Marchal F, Classe JM, Ferron G, Guilloit JM, Meeus P, Goéré D, Bonastre J. Complete cytoreductive surgery plus intraperitoneal chemohyperthermia with oxaliplatin for peritoneal carcinomatosis of colorectal origin. J Clin Oncol 2009;27:681-5.

26. Kleivi K, Lind GE, Diep CB, Meling GI, Brandal LT, Nesland JM, Myklebost O, Rognum TO, Giercksky KE, Skotheim RI, Lothe RA. Gene expression profiles of primary colorectal carcinomas, liver metastases, and carcinomatoses. Mol Cancer $2007 ; 6: 2$.

27. Nishimori H, Yasoshima T, Denno R, Shishido T, Hata F, Okada Y, Ura H, Yamaguchi K, Isomura H, Sato N and Hirata K. A novel experimental mouse model of peritoneal dissemination of human gastric cancer cells: Different mechanisms in peritoneal dissemination and hematogenous metastasis. Jpn J Cancer Res 2000;91:715-22.

28. Logan-Collins JM, Lowy AM, Robinson-Smith TM, Kumar S, Sussman JJ, James LE, Ahmad SA. VEGF expression predicts survival in patients with peritoneal surface metastases from mucinous adenocarcinoma of the appendix and colon. Ann Surg Oncol 2008;15:738-44. 
Table 1: Patients' demographic and primary tumor characteristics

Variable

Sex

Male, n (\%)

$75(51)$

Female, $\mathrm{n}(\%)$

$71(49)$

Median age (range)

$56(19-76)$

Primary tumor and carcinomatosis, n (\%)

Synchronous

$45(31)$

Metachronous

$101(69)$

Histological diagnosis, n (\%)

Mucinous

$95(65)$

Intestinal

$51(35)$

Unfavorable peritoneal sites, $\mathrm{n}(\%)$

$18(12)$

ECOG, n (\%)

$\leq 2$

$>2$

$146(100)$

$0(0)$

Site of the primary tumor, n (\%)

Right colon

$51(35)$

Left colon

$95(65)$

Peritoneal cancer index (PCI), n (\%)

$<11$

$48(32.9)$

$11-20$

$72(49.3)$

$>20$

$26(17.8)$

Median follow-up, months (range)

$19(1-108)$ 
Table 2. Tumor and treatment characteristics with median survival of the various subgroups that underwent cytoreductive surgery combined with hyperthermic intraperitoneal chemotherapy for colorectal carcinomatosis. Univariate and multivariate analysis.

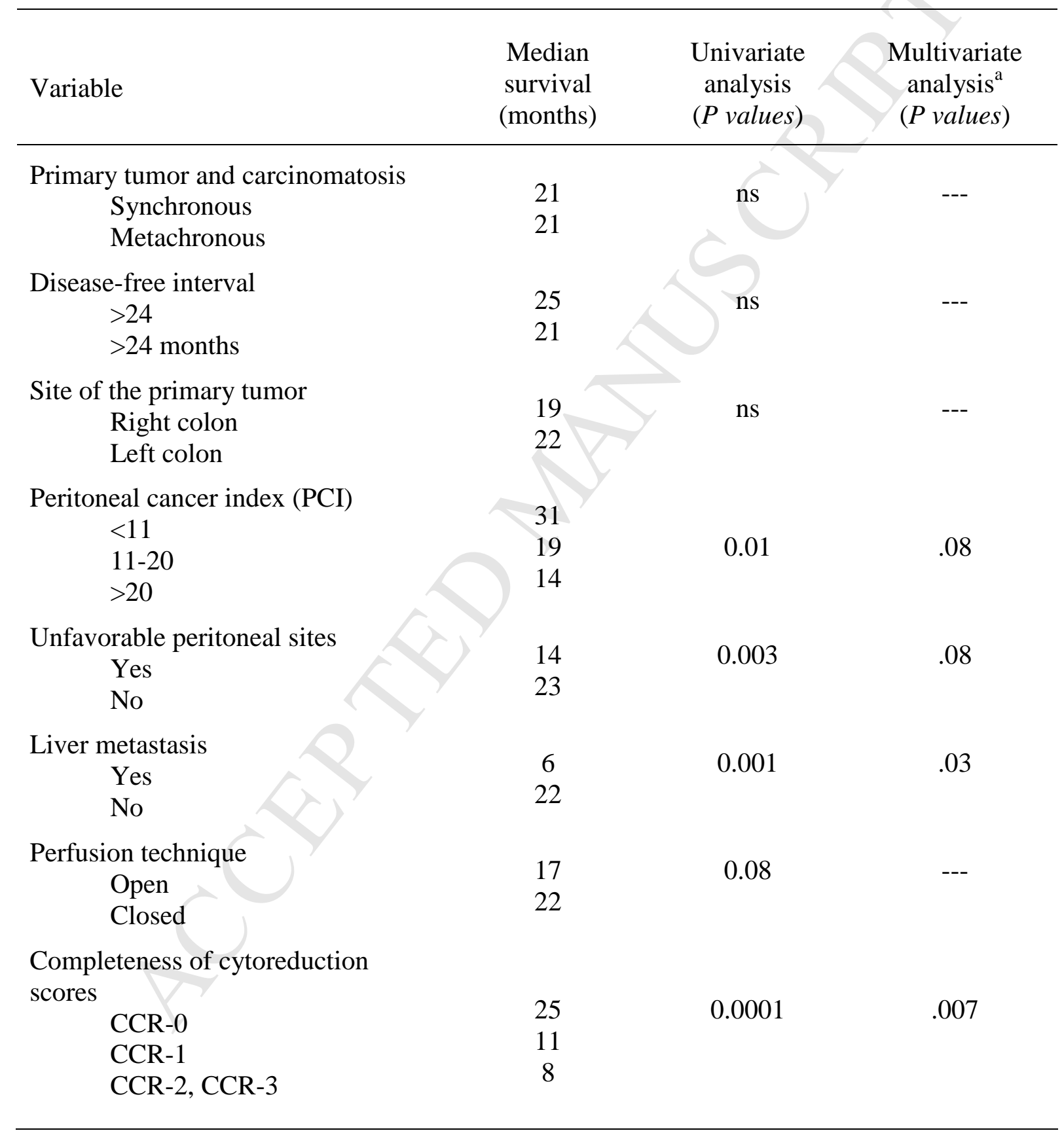

${ }^{\text {a }} P$-values $<0.10$ are considered to indicate statistical significance. 


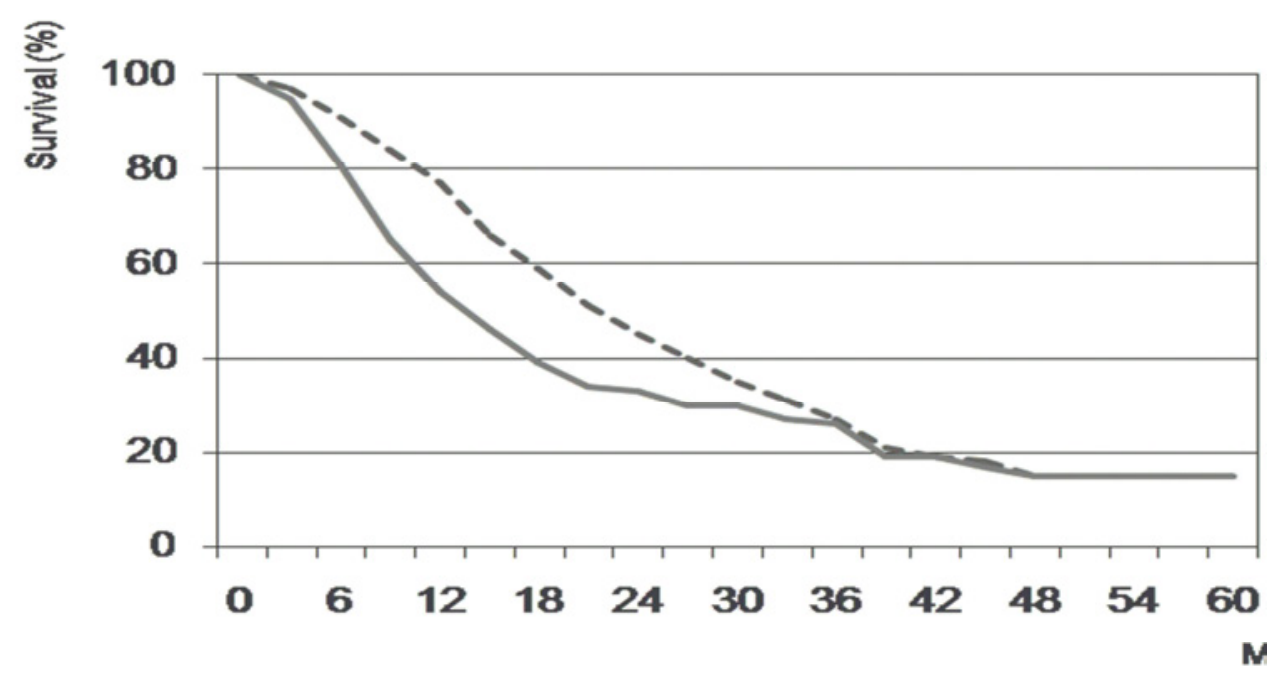




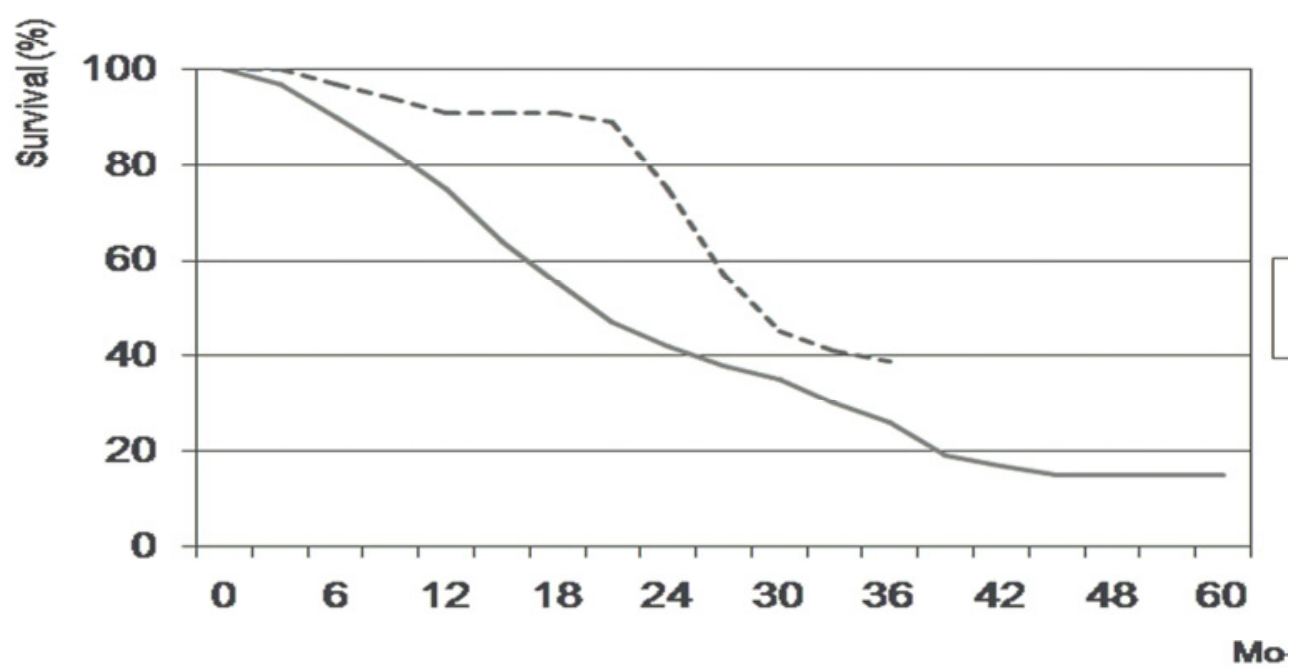




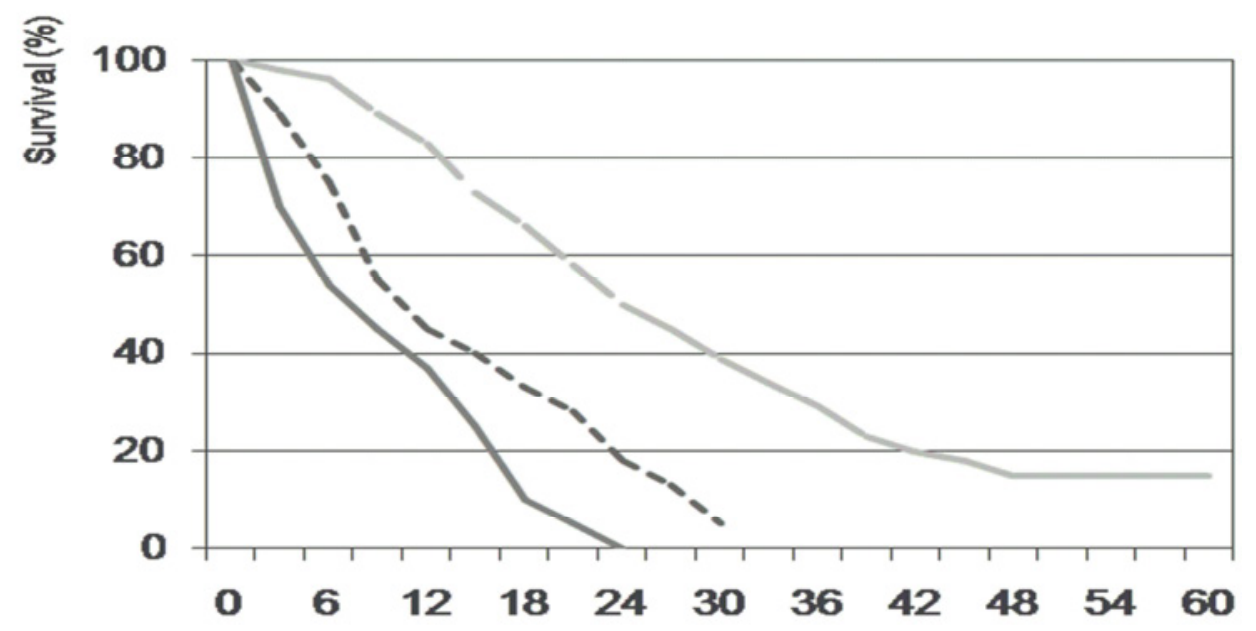

